\title{
Screening of vegetables crop genotype against root-knot nematode (Meloidogyne incognita) under polyhouse conditions
}

\author{
Vinod Kumar*, S. S. Mann and Anil Kumar \\ Department of Nematology, C.C.S. Haryana Agricultural University, Hisar (Haryana) India \\ (Email: vinodnagal09@gmail.com)
}

\begin{abstract}
Root-knot nematode, Meloidogyne incognita is an economically important plant-parasitic nematode of vegetable crops grown under open as well as protected cultivation. Use of resistant cultivar is an important measure for managing root-knot nematode as compared to the other management strategies. Despite the potential importance of this nematode, sources of resistance to $M$. incognita are not yet available for breeding purposes. Present studies were conducted to evaluate the resistant reaction of crop genotype (cucumber japanes long green, tomato shu, cherry tomato P. cherry tomato-1, bitter gourd pusa aushadhi and capsicum yalo wonder) against $M$. incognita under polyhouse conditions (2018-20). Sixty days after sowing, observations were recorded on number of galls/plant and final nematode population. All the crop genotypes of vegetables were showed varying degree of response against $M$. incognita. Out of five crop genotypes of vegetables, four (cucumber japanes long green, tomato shu, cherry tomato P. cherry tomato-1 and bitter gourd Pusa aushadhi) were susceptible/highly susceptible while capsicum yalo wonder showed moderately resistant reaction against $M$. incognita in both the years (2018-2020) and this genotype can be used as a source of resistance.
\end{abstract}

Key Words : Meloidogyne incognita, Polyhouse, Screening, Tomato, Cucumber, Capsicum, Bitter gourd

View Point Article : Kumar, Vinod, Mann, S.S. and Kumar, Anil (2021). Screening of vegetables crop genotype against root-knot nematode (Meloidogyne incognita) under polyhouse conditions. Internat. J. agric. Sci., 17 (2) : 600-603, DOI:10.15740/HAS/IJAS/17.2/600-603. Copyright@ 2021: Hind Agri-Horticultural Society.

Article History : Received : 23.03.2021; Revised : 30.03.2021; Accepted : 07.04.2021

\footnotetext{
* Author for correspondence :
} 